\title{
Caspases mediate nucleoporin cleavage, but not early redistribution of nuclear transport factors and modulation of nuclear permeability in apoptosis
}

\author{
E Ferrando-May ${ }^{1}$, V Cordes $^{2,3}$, I Biller-Ckovric ${ }^{1}, \mathrm{~J} \mathrm{Mirkovic}^{1}$, \\ D Görlich ${ }^{4}$ and P Nicotera ${ }^{\star, 5}$ \\ ${ }^{1}$ Chair of Molecular Toxicology, Department of Biology, University of Konstanz, \\ 78457 Konstanz, Germany \\ 2 Karolinska Institutet, Medical Nobel Institute, Department of Cellular and \\ Molecular Biology, S-17177 Stockholm, Sweden \\ ${ }^{3}$ Division of Cell Biology, Germany Cancer Research Center, D-69120, \\ Heidelberg, Germany \\ ${ }^{4}$ Zentrum für Molekulare Biologie der Universität Heidelberg, D-69120, \\ Heidelberg, Germany \\ ${ }^{5}$ MRC Toxicology Unit, Hodgkin Building, University of Leicester, Lancaster \\ Road, Leicester LE1 9HN, UK \\ * Corresponding author: P Nicotera, MRC Toxicology Unit, Hodgkin Building, \\ University of Leicester, Lancaster Road, Leicester LE1 9HN, UK. \\ Tel +44-116-2525611; Fax: +44-116-2525616; E-mail: pn10@leicester.ac.uk
}

Received 23.11.00; revised 22.12.00; accepted 29.12.00

Edited by M Piacentini

\begin{abstract}
In eukaryotic cells, both soluble transport factors and components of the nuclear pore complex mediate protein and RNA trafficking between the nucleus and the cytoplasm. Here, we investigated whether caspases, the major execution system in apoptosis, target the nuclear pore or components of the nuclear transport machinery. Four nucleoporins, Nup153, RanBP2, Nup214 and Tpr are cleaved by caspases during apoptosis. In contrast, the nuclear transport factors, Ran, importin $\alpha$ and importin $\beta$ are not proteolytically processed, but redistribute across the nuclear envelope independently and prior to caspase activation. Also, mRNA accumulates into the nucleus before caspases become active. Microinjection experiments further revealed that early in apoptosis, the nucleus becomes permeable to dextran molecules of $70 \mathrm{kD}$ molecular weight. Redistribution of import factors and mRNA, as well as nuclear permeabilisation, occur prior to caspasemediated nucleoporin cleavage. Our findings suggest that the apoptotic programme includes modifications in the machinery responsible for nucleocytoplasmic transport, which are independent from caspase-mediated degradation of nuclear proteins. Cell Death and Differentiation (2001) 8, 495-505.
\end{abstract}

Keywords: caspase; nuclear pore complex; nuclear import; mRNA export; microinjection

Abbreviations: aa, amino acids; NLS, nuclear localisation sequence; WGA, wheat germ agglutinin; STS, staurosporine; ActD, actinomycin D; DEVD-afc, N-acetyl-Asp-Glu-Val-aspartylaminofluoro-methylcoumarine; z-VAD-fmk, N-benzyloxycarbonyl-
Val-Ala-aspartyl-fluoromethylketone; DEVD-CHO, N-acetyl-AspGlu-Val-Asp-aldehyde

\section{Introduction}

The most evident morphological feature of apoptosis is the disassembly of the nucleus, which involves the condensation of chromatin and its segregation into membrane-enclosed particles. ${ }^{1}$ Biochemical hallmarks of apoptotic nuclear execution are DNA cleavage in large and small (oligonucleosomal-sized) fragments, as well as the specific proteolysis of several nuclear substrates. Major effectors of apoptotic nuclear changes are members of the cysteine protease family of caspases. Nuclear substrates for caspases include nucleoskeletal elements like lamins, ${ }^{2,3}$ and proteins involved in the organisation and replication of DNA, like SAFA, MCM3 and RCF140. ${ }^{4-6}$

Cleavage of nuclear proteins may have important implications for the apoptotic process. For example, PARP cleavage shuts down its ADP-ribosylating activity, preventing a futile recruitment of the DNA-repair machinery and sparing ATP necessary for the apoptotic execution. ${ }^{7}$ Similarly, cleavage of MCM proteins and replication factor 140 may inhibit unnecessary DNA replication cycles. Recent findings also show that a nuclear pore protein Nup153 is cleaved in apoptosis. ${ }^{8}$ This protein, which belongs to the XFXFG-family of nucleoporins and resides at the nucleoplasmic side of the pore as a constituent of the nuclear basket ${ }^{9}$ (see also ${ }^{10,11}$ ), has been implicated in various types of nuclear protein import as well as mRNA export from the nucleus. ${ }^{12,13}$ Nup153 has been shown to bind soluble components of the nuclear transport machinery, such as members of the importin $\beta$ family and the small GTPase Ran. ${ }^{14,15}$ Therefore cleavage of Nup153 by caspases may affect nucleocytoplasmic transport in cells undergoing apoptosis.

A potential role of nucleocytoplasmic transport processes in apoptotic execution has been first inferred by Yasuhara et al., ${ }^{16}$ who showed that microinjection of different inhibitors of nuclear import including WGA (wheat germ agglutinin), a lectin binding to several O-glycosylated nucleoporins, protected from Fas-induced apoptotic nuclear changes. WGA was also reported to prevent nuclear condensation elicited by the apoptosis-inducing factor $\mathrm{AlF}^{17}$ or by Acinus (apoptotic chromatin condensation inducer in the nucleus). ${ }^{18}$ Even though WGA may bind other factors than nucleoporins, ${ }^{19}$ these experiments suggest that active nuclear translocation of apoptosis executioners may be required for nuclear degradation. In line with this assumption is the finding that procaspase-1 and -2 , as well as the caspase-activated DNAse CAD, carry nuclear localisation sequences (NLSs)..$^{20-22}$ 
Since the integrity of the nuclear pore may be essential for nucleocytoplasmic transport, we initially studied the fate of several representative nucleoporins in apoptosis. In addition to Nup153 these included RanBP2, Nup214, Tpr and p62, each of which is a constituent of a different substructure of the NPC. RanBP2, a Ran-binding protein of $358 \mathrm{kD}$, and Nup214 are XFXFG-type nucleoporins located at the short filaments attached to the cytoplasmic side of the NPC. ${ }^{11,23-26}$ p62, which represents another XFXFG nucleoporin, is located at or near the center of the NPC. ${ }^{27-30} \mathrm{Tpr}$, a protein of $267 \mathrm{kD}$ which lacks XFXFG sequence motifs, is a constitutive element of thin filaments which are attached to the NPC's nucleoplasmic side and which project into the nuclear interior beyond the dimensions of the nuclear basket. ${ }^{31,32}$ We found that Nup153, RanBP2, Nup214 and Tpr, but not p62, are specifically and rapidly cleaved by a distinct set of caspases during apoptosis.

We then analyzed a subset of nuclear transport factors, some of which are known to interact with Nup153, RanBP2 or Tpr. These are importin $\beta$, the major receptor for classical NLS-dependent import, importin $\alpha$, an adapter molecule which mediates the interaction between importin $\beta$ and the NLS-bearing transport substrate, and Ran, a Rasfamily GTPase which controls the binding of transport receptors to their substrates. ${ }^{33}$ We discovered that Ran, importin $\alpha$ and importin $\beta$ are not degraded but redistributed between the nucleus and the cytoplasm in the early phase of apoptosis. Concomitantly, poly $(A)^{+}-$RNA accumulated in the nucleus.

Both the relocalisation of transport factors and nuclear mRNA accumulation occurred prior to caspase-mediated chromatin condensation, and independently from caspasemediated cleavage of nucleoporins. Taken together our findings suggest the existence of caspase-independent pathways that signal to the nucleus the initiation of the death programme.

\section{Results}

\section{Cleavage of nucleoporins Nup153, RanBP2, Nup214 and Tpr in HeLa cells undergoing apoptosis}

To investigate the fate of nuclear pore complex proteins in apoptosis, we treated HeLa cells with two classic apoptotic triggers: staurosporine (STS), a general protein kinase inhibitor, which induces apoptosis in many different cell types, ${ }^{34}$ and actinomycin D (ActD), an inhibitor of RNA polymerases, used as a stimulus acting primarily on the nucleus. $^{35}$

After $3 \mathrm{~h}$ of exposure to STS and $6 \mathrm{~h}$ of exposure to ActD, about $50 \%$ of the cells underwent apoptosis as judged by nuclear condensation. Concomitantly, we measured a 30 -fold increase in the cleavage of the caspase substrate DEVD-afc, compared to control cells, which showed the efficient activation of caspase-3 like proteases (Figure 1). Both cell death and caspase activation were effectively inhibited by the poly-caspase inhibitor zVAD-fmk $(20 \mu \mathrm{M}) .^{36}$
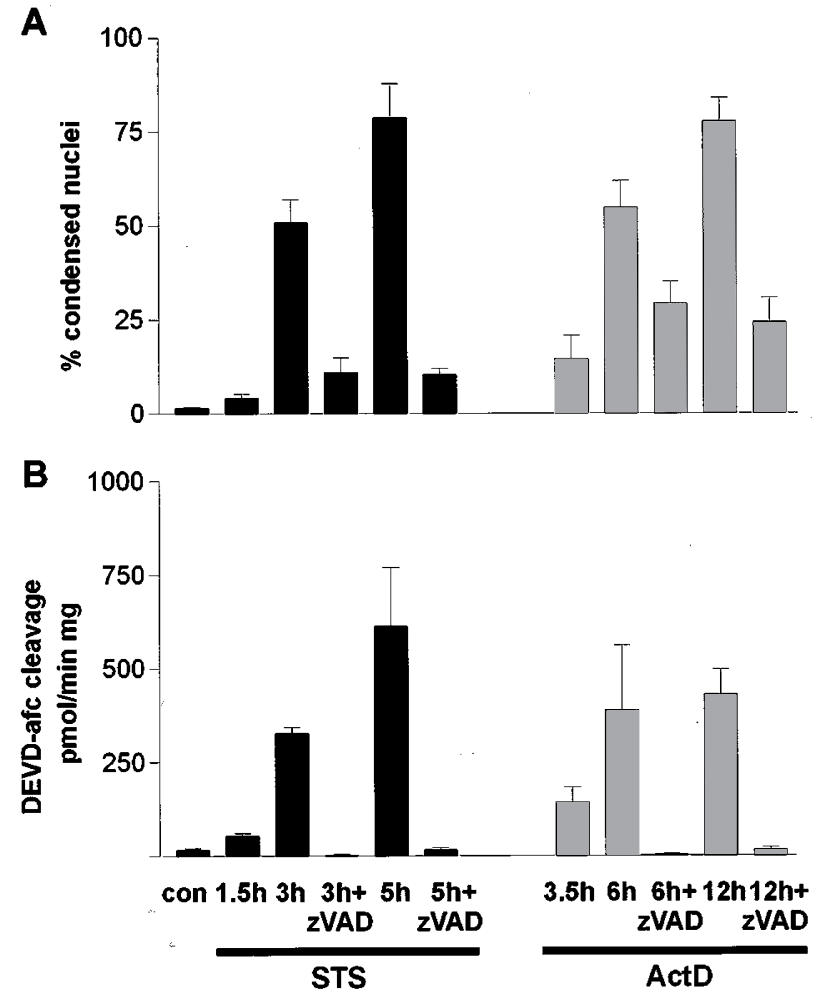

Figure 1 Staurosporine (STS) and actinomycin D (ActD) induced cell death in HeLa cells. (A) Apoptosis was quantified by staining cells with $\mathrm{H}-33342$ and Sytox and scoring Sytox-impermeable cells with condensed nuclei. (B) Caspase-3 like activity was determined by DEVD-afc cleavage. Data are means \pm standard deviation from triplicate determinations. Con: control cells

Whole cell extracts from treated HeLa cells were incubated with the polyspecific antibody Mab414 which recognises several members of the XFXFG-family of nucleoporins including RanBP2, Nup153, p62 and others. $^{9,27}$ As shown in Figure 2, primarily two proteins with electrophoretic mobilities corresponding to $\mathrm{Mr}$ of 350 and 180 were degraded. Their cleavage was suppressed by preincubation with zVAD-fmk. Immunoblotting with specific antibodies identified the two cleaved nucleoporins as RanBP2 and Nup153 (Figure 3). One major degradation intermediate, recognised by different Nup153-specific antibodies, was a polypeptide of $\mathrm{Mr} \mathrm{130}$. This fragment most likely corresponds to the Mab414-reactive $130 \mathrm{kD}$ polypeptide enriched in apoptotic cells (see Figure 2). A Nup153 degradation product of $130 \mathrm{kD}$ has recently also been observed by others. ${ }^{8}$ Proteolytic processing of RanBP2 was monitored with an antibody specific for an epitope in the protein's C-terminal half. In this case, three cleavage products of 170,220 and $250 \mathrm{kD}$ were labelled. Cleavage of a further XFXFG-nucleoporin, Nup214, yielded a fragment of $120 \mathrm{kD}$, which became apparent only after long exposure times. In contrast, the other member of the XFXFG-family, p62, was not degraded (Figure 3), indicative that cleavage of RanBP2, Nup214 and Nup153 did not merely reflect an overall and simultaneous destruction of the nuclear pore complex. 


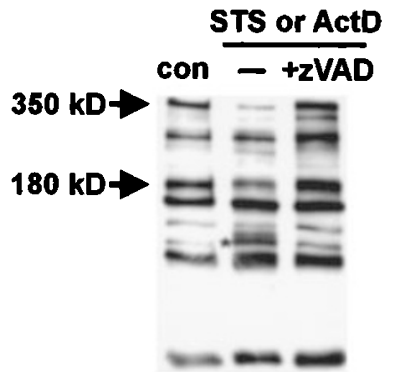

Mab414

Figure 2 Proteolysis of XFXFG-nucleoporins in apoptosis. Whole HeLa cell extracts were prepared from control cells and apoptotic cells treated with staurosporine (STS) or actinomycin D (ActD) in absence or in presence of zVAD-fmk followed by immunoblotting with the polyspecific antibody Mab414. The asterisk indicates the $130 \mathrm{kD}$ cleavage product of Nup153

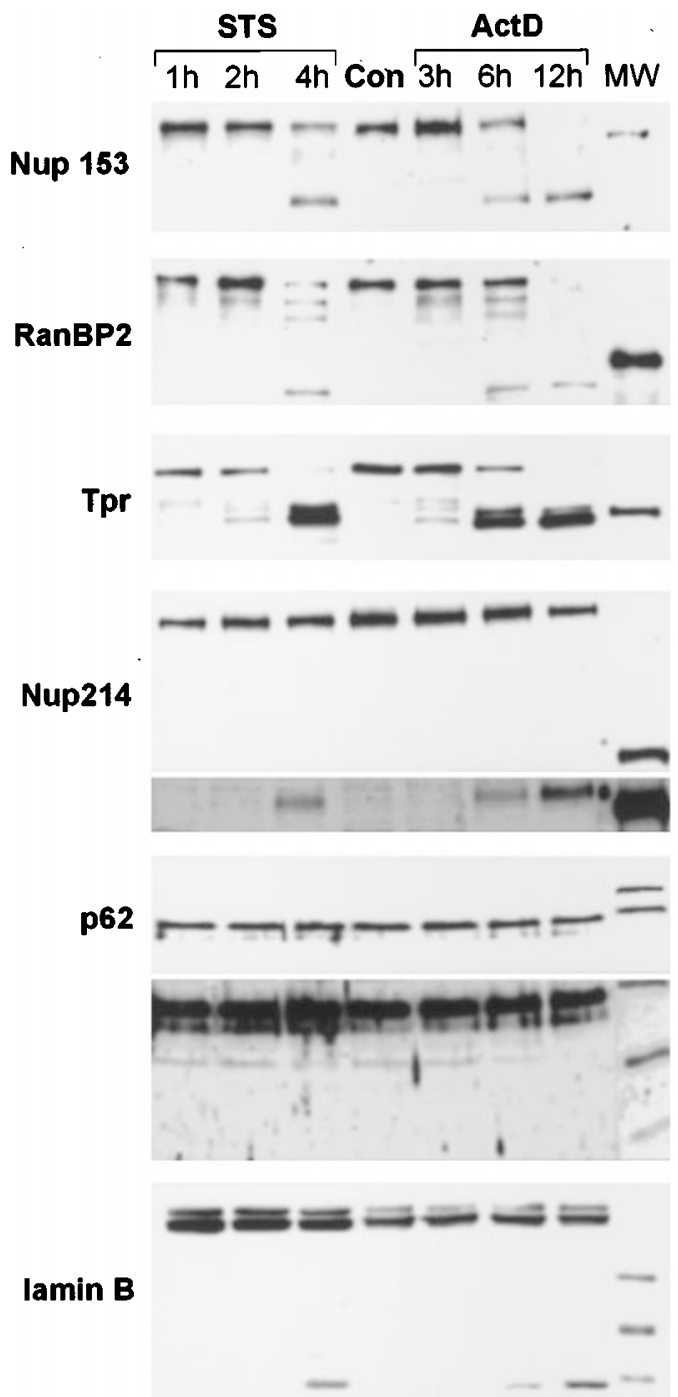

[KD] 165

200

200

116.2

116.2

97.4

66.2

66.2

46.5

37.5

46.5

37.5

28.0

Figure 3 Nup153, RanBP2, Tpr and CAN/Nup214 are cleaved in apoptosis. Whole cell extracts were prepared from control cells (con) and apoptotic cells treated with staurosporine (STS) and actinomycin D (ActD) at the indicated time points followed by immunoblotting with antibodies specific for the indicated nucleoporins. Long exposures of the Nup214 and p62 blots are included. Cleavage of lamin B as marker for apoptosis is also shown
To investigate whether other, non-XFXFG nucleoporins, were also targets of apoptotic degradation, we studied the fate of the NPC-associated protein Tpr. Induction of apoptosis resulted in cleavage of Tpr yielding two immunoreactive degradation products: a minor one of $200 \mathrm{kD}$ and a major fragment of $190 \mathrm{kD}$.

Cleavage of Nup153, RanBP2, Nup214 and Tpr occurred $4 \mathrm{~h}$ after STS and $6 \mathrm{~h}$ after ActD treatment and coincided with the degradation of lamin $B$, which has been widely used as a marker for the onset of apoptotic nuclear execution. ${ }^{3}$

To narrow in the cleavage sites on Nup153 and Tpr, we then used peptide specific antibodies which were raised against different regions of these proteins. As seen in Figure 4, the Nup153 cleavage product was recognised by an antibody specific for a peptide comprising aa 391 to 404 ( $\alpha$-Nup153-3), but not by an antibody directed against the very $\mathrm{N}$-terminus of the protein ( $\alpha$-Nup153-1), suggesting that cleavage occurred between aa 36 and 391 . This region contains one sequence with homology to caspase recognition sites (DITD at position 343). Cleavage at this
A

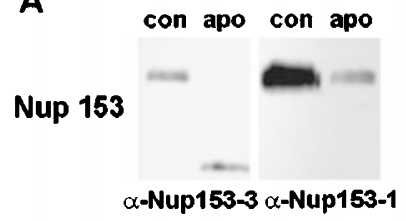

C

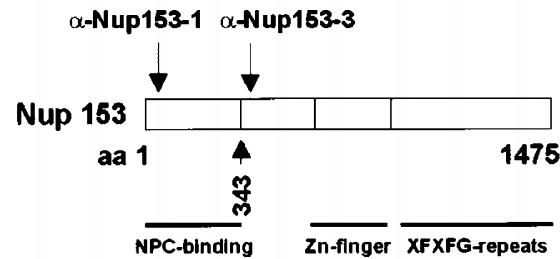

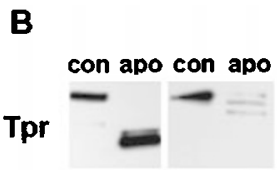

$\alpha-T p r 1 \alpha-$ Tpr 2

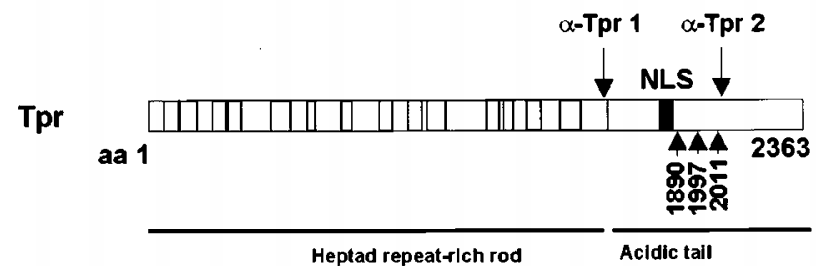

Figure 4 Mapping of Nup153 and Tpr cleavage products. (A) Whole HeLa cell extracts from control cells (con) and apoptotic cells (apo) were immunoblotted with antibodies against specific regions of the proteins. (B) Schematic representation of the Nup153 and Tpr primary structures. The tripartite structure of Nup153 consists of NPC-binding domain, zinc finger region, and XFXFG-repeat domain. The Tpr protein is divided into two major domains, a coiled-coil dominated, heptad repeat-rich rod domain, and an acidic carboxyterminal one which contains the protein's nuclear localization signal (NLS). Amino- and carboxyterminal amino acids (aa), the location of putative caspase cleavage sites (short arrows) and the relative position of the epitopes recognised by the peptide-specific antibodies used in this investigation (long arrows) are indicated 
site would result in a polypeptide with a predicted $\mathrm{MW}$ of $126 \mathrm{kD}$, which fits well with the size of the fragment observed in the Western blot.

In the case of Tpr, the two cleavage products of 190 and $200 \mathrm{kD}$ were recognised only by an antibody directed against a peptide stretching from aa 1622 to $1640(\alpha-T p r-1)$, whereas an antibody binding to aa 2063-2084 ( $\alpha$-Tpr-2) failed to give a signal. The region between aa 1640 and 2063 contains three putative caspase cleavage sites at positions $D_{1890}, D_{1997}$ and $D_{2011}$. While cleavage at position 1890 may give rise to the fragment of $190 \mathrm{kD}$, the second fragment could originate either by cleavage at aa 1997 or 2011. The size difference between the major and the minor fragment would be in both cases $12-14 \mathrm{kD}$, which agrees with the separation between the two Tpr-specific bands observed in the Western blot.

A variety of specific protease inhibitors were then tested for their ability to inhibit nucleoporin cleavage. In the STS model, cleavage of Nup153 and Tpr was most effectively, if not exclusively, inhibited by zVAD-fmk and DEVD-CHO, indicating that cleavage of these nucleoporins is dependent on caspase activity (Figure 5). Identical results were obtained also for Nup214 (not shown). Caspase inhibitors prevented processing also of RanBP2 to the $220 \mathrm{kD}$ and $170 \mathrm{kD}$, but not to the $250 \mathrm{kD}$ fragment. Of the other protease inhibitors, only calpain inhibitor I inhibited cleavage of RanBP2. This may reflect the broad inhibition

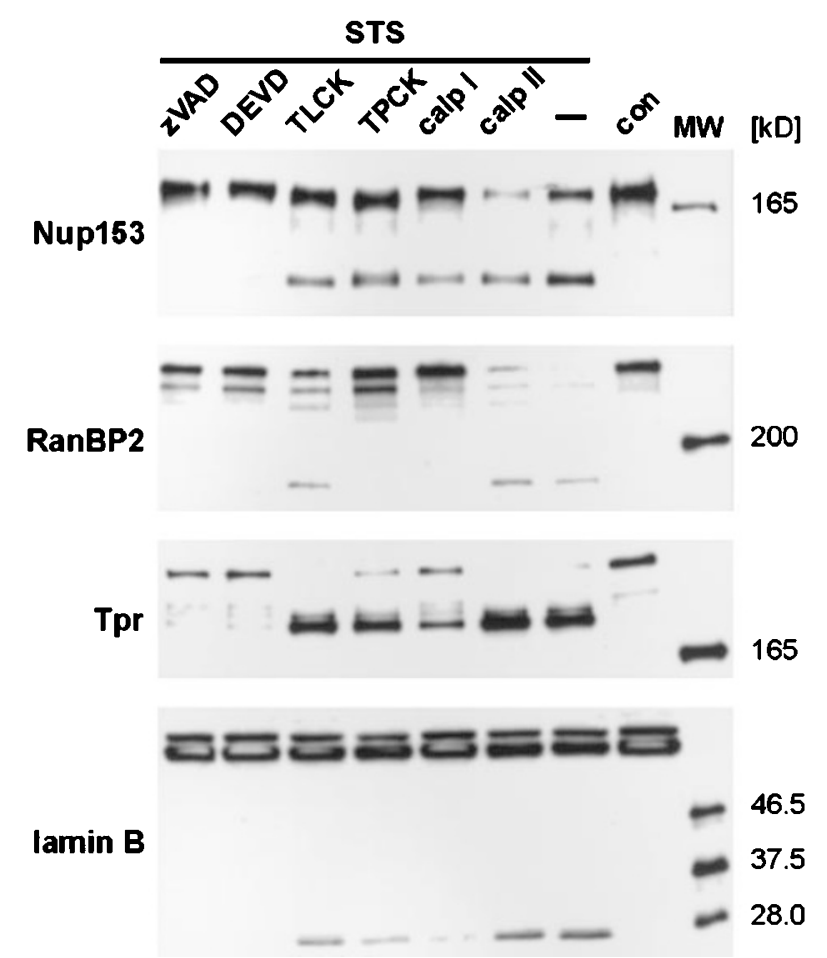

Figure 5 Nucleoporin cleavage is prevented by caspase inhibitors. HeLa cells were treated with staurosporine (STS) for $4 \mathrm{~h}$ in the presence or absence of different protease inhibitors. Whole cell extracts of STS-treated and contro cells (con) were then analyzed by immunoblotting with nucleoporin-specific antibodies. Inhibition of lamin B cleavage is shown as reference spectrum of this inhibitor or the possibility that besides caspases, calpains may also be involved in RanBP2 proteolysis during apoptosis.

To confirm that caspases are responsible for the cleavage of Tpr and Nup153 we incubated permeabilised cells in the presence of different purified recombinant caspases. As shown in Figure 6, the Nup153 signature fragment at $130 \mathrm{kD}$ was found only after incubation with caspase 3. Also other caspases cleaved Nup153 in the in vitro assay, but these gave rise to fragments clearly different from those seen in vivo: Caspase 1 consistently degraded Nup153 almost to completion, while caspase 8 yielded a weak band at $150 \mathrm{kD}$.

The in vivo cleavage pattern of Tpr, with the two proteolytic fragments at 190 and $200 \mathrm{kD}$ was reproduced in vitro only after incubation with caspase 1 , thus identifying Tpr as a substrate for this caspase in apoptosis. Caspase 3 cleaves Tpr only to the $190 \mathrm{kD}$ fragment, possibly explaining why, in vivo, this fragment is more abundant compared to the $200 \mathrm{kD}$ fragment, since in cells, Tpr may be cleaved by both caspases concomitantly.

Taken together, our results show that Nup153, RanBP2, Nup214 and Tpr are cleaved by caspases in the course of apoptosis. This cleavage is independent from the apoptotic stimulus, since it occurs in two distinct models of cell death and thus is likely to be a constitutive part of the apoptotic execution programme. 


\section{Nuclear transport factors are abnormally distributed in apoptotic cells}

After having analyzed the cleavage of Nup153, RanBP2, Nup214 and Tpr in apoptosis, we studied the fate of shuttling nuclear transport factors that reportedly bind to these nucleoporins, i.e. importin $\alpha$, importin $\beta$ and Ran. ${ }^{14,15,37-39}$ We also studied the components of the Ran cycle, RanGAP1, a GTPase activating protein for $\operatorname{Ran}^{40}$ and RCC1, its nucleotide exchange factor. ${ }^{41}$ In non-apoptotic interphase cells, these proteins exhibit a characteristic subcellular distribution: the majority of Ran is located within the nuclear interior, while the importins are found mainly in the cytoplasm. A small fraction of importin $\beta$ is also known to occur bound to the NPCs. ${ }^{42,43}$ RanGAP1 occurs in two fractions, one cytoplasmic and the other, which is modified by a small ubiquitin like peptide, is attached at the nuclear pore via binding to RanBP2. ${ }^{44-47} \mathrm{RCC} 1$ is a nuclear protein which binds to chromatin. ${ }^{48}$

Immunofluorescence analysis of Ran in control cells showed the expected nucleoplasmic localisation of the protein with exclusion of the nucleoli (Figure 7). Upon treatment with STS and ActD the protein redistributed from the nuclear compartment to the cytosol. This occurred in cells with no visible sign of chromatin condensation. Although Ran still accumulated in the nucleus, the concentration gradient over the nuclear membrane was visibly diminished and nucleolar exclusion was lost.

Under control conditions, importin $\beta$ and importin $\alpha$ localised mainly to the cytoplasm and to a small fraction at the nuclear membrane. After treatment with both STS and ActD, the importin $\beta$-specific signal in the nucleus visibly increased, indicating a redistribution of the protein, while nuclear rim staining was retained. Redistribution of importin
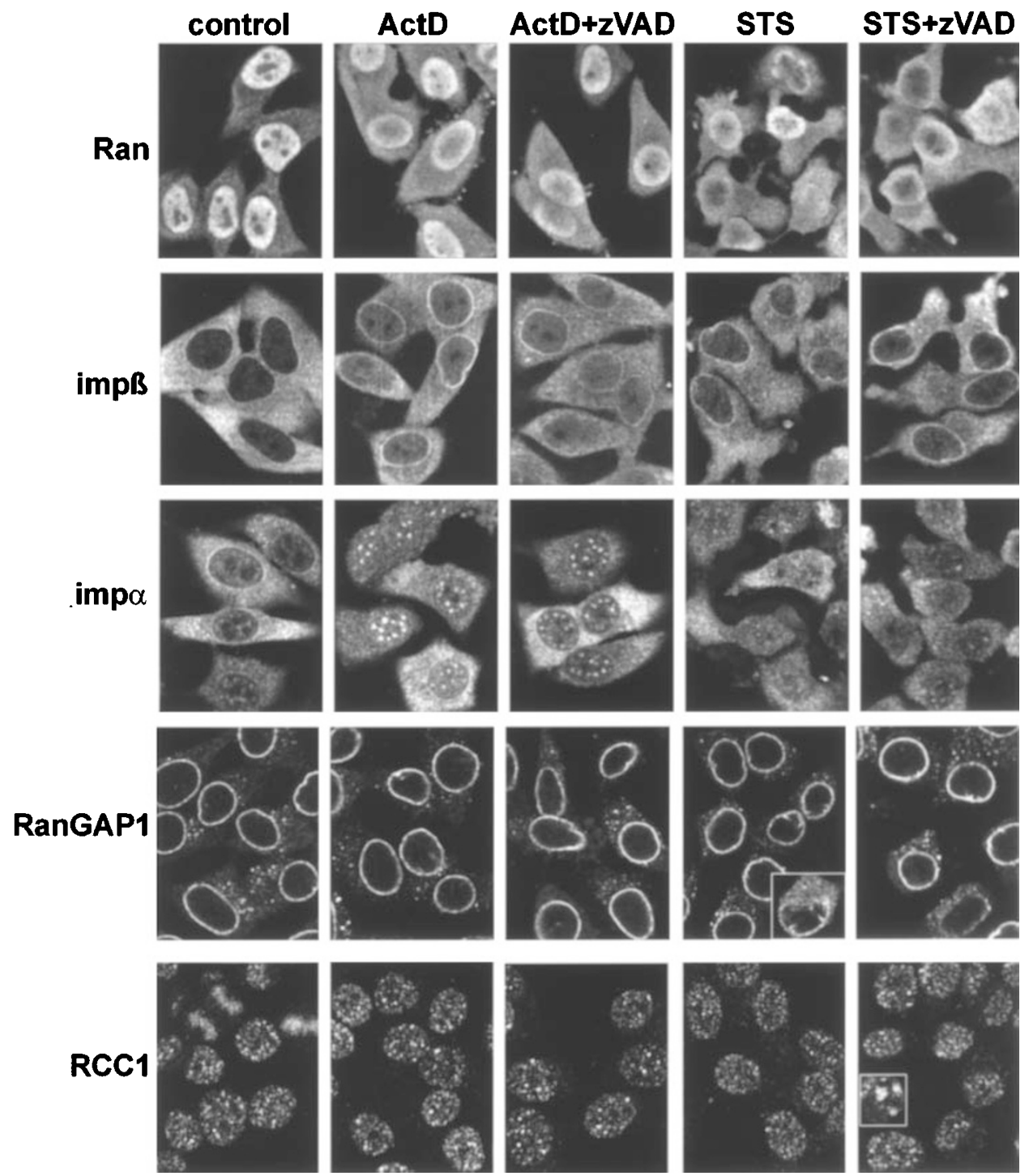

Figure 7 Ran, importin $\beta$ and importin $\alpha$ are relocalised during apoptosis. HeLa cells fixed $1.5 \mathrm{~h}$ after staurosporine (STS) and $3.5 \mathrm{~h}$ after actinomycin D (ActD) stimulation in the absence or presence of the caspase inhibitor ZVAD-fmk were stained with the specified antibodies as described. The inset in the panel with RanGAP1 immunostaining of STS-treated cells shows a late apoptotic cell with increased cytoplasmic RanGAP1 staining 
$\alpha$ was clearly detectable only in STS-treated cells, where nuclear rim staining was completely lost, whereas after ActD treatment, importin $\alpha$ appeared in speckled structures in the nucleus. Relocalisation of both importins occurred prior to chromatin condensation.

In contrast, localisation of RanGAP1 at the nuclear rim was not affected until the nuclei were completely condensed (see insert in Figure 7). In these late apoptotic cells, the RanGAP1 signal in the cytoplasm clearly increased, indicating dissociation of the protein from the NPC. Similarly, RCC1 distribution was not influenced by treatment with apoptosis inducers until the stage of chromatin condensation. In late apoptotic nuclei, RCC1 staining changed from a finely punctate pattern to a clumpy appearance reflecting its association with the condensed DNA.

To ensure that changes in fluorescence distribution were not caused by proteolytic degradation of the factors themselves, we examined their integrity by immunoblotting. As shown in Figure 8, Ran, RanGAP1, RCC1, importin $\beta$ and importin $\alpha$ were present in constant amounts in HeLa cells undergoing apoptosis. We could not detect any sign of proteolytic cleavage, confirming that the altered pattern of immunofluorescence observed in apoptotic cells reflected a true change in the localisation of the proteins.

Most importantly, redistribution of Ran, importin $\beta$ and importin $\alpha$ occurred already at $1.5 \mathrm{~h}$ after STS and $3.5 \mathrm{~h}$ after ActD treatment, i.e., when caspases were not yet active (see Figure 1) and nuclei did not exhibit any sign of

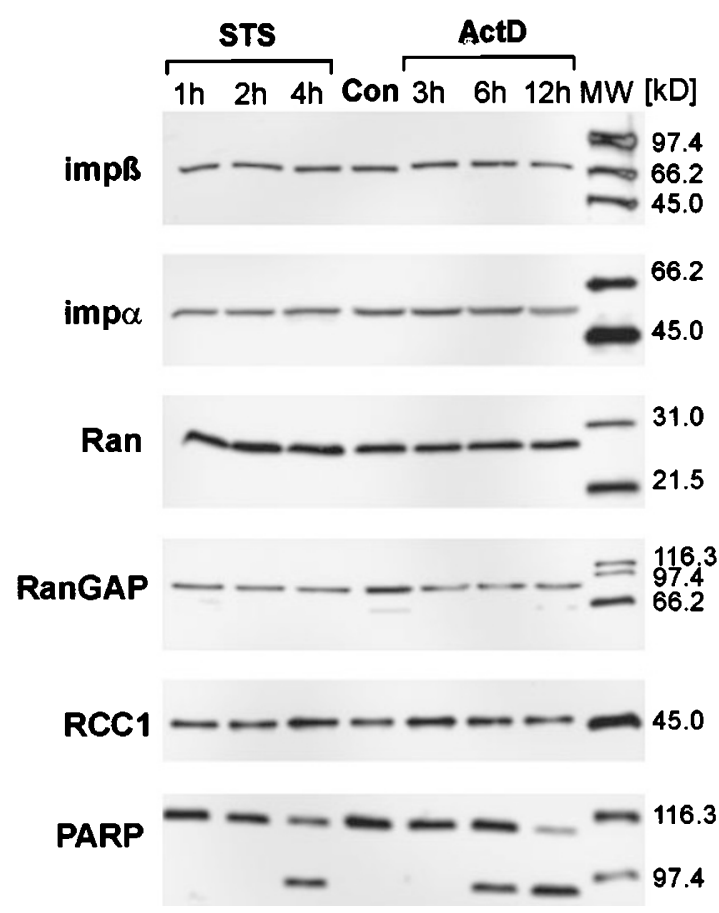

Figure 8 Nuclear transport factors are not degraded during apoptosis. While HeLa cell extracts were prepared from control cells and apoptotic cells treated with staurosporine (STS) and actinomycin D (ActD) at the indicated time points followed by immunoblotting with antibodies specific for importin $\beta$, importin $\alpha$, Ran, RanGAP1 and RCC1. Cleavage of PARP as marker for apoptosis is shown as reference chromatin condensation. At these time points, cytochrome $c$ release, an indicator for the activation of the caspase 9 pathway, ${ }^{49}$ had not yet occurred (not shown). Additionally, redistribution was not affected by zVAD-fmk at concentrations that protected from apoptosis and completely abolished nucleoporin cleavage.

This implies, that nucleoporin cleavage was not causally linked to the observed relocalisation of Ran and importins, and that caspase-independent signals are directed to the nuclear transport machinery early during the execution of the apoptotic programme.

\section{The permeability of the nuclear pore is altered at an early stage of apoptosis}

The redistribution of nuclear transport factors in early apoptotic cells may have resulted from a loss of selectivity of the nuclear permeability barrier, allowing for unrestrained passage of these factors through the nuclear pore. We therefore decided to probe the permeability of the nuclear barrier during apoptosis by microinjecting fluorescent dextrans into the cytoplasm of HeLa cells and following their distribution after apoptotic stimulation. To this purpose we tried dextrans with three different molecular weights: $40 \mathrm{kD}$ being in the range of the exclusion limit of the nuclear pore, $70 \mathrm{kD}$ and $150 \mathrm{kD}$ clearly exceeding the exclusion limit, but differing in their diffusion rates. ${ }^{50}$

The $40 \mathrm{kD}$ dextran equilibrated between the nucleus and the cytoplasm during the recovery of the cells after microinjection, whereas the $150 \mathrm{kD}$ did not enter the nucleus until caspases were active and nucleoporins and lamins were cleaved (not shown). In untreated cells, the $70 \mathrm{kD}$ dextran was also, as expected, efficiently excluded from the nucleus and its diffusion was not rate-limiting.

Nuclear penetration to $70 \mathrm{kD}$ dextran was detected $1.5 \mathrm{~h}$ after stimulation with STS (Figure 9). In addition, zVAD-fmk did not prevent $70 \mathrm{kD}$ dextran permeation into the nucleus, showing that modulation of the diffusion diameter of the NPC is also independent from caspases.

\section{poly $(A)^{+}$-RNA accumulates in nuclei of cells committed to apoptosis}

Based on the observation that early in apoptosis the permeability of the nuclear envelope increases and nuclear transport factors are relocalised, we investigated whether macromolecular trafficking across the nuclear membrane may be altered concomitantly. To this end, we studied the distribution of mRNA in non-apoptotic and stimulated HeLa cells by in situ hybridisation with a biotinylated oligo-dT 45mer. As shown in Figure 10, control HeLa cells showed a high cytoplasmic poly $(A)^{+}$-RNA content compared to the nucleus, which exhibited a faint staining with nucleolar exclusion. Treatment with STS for $1.5 \mathrm{~h}$ induced an increase in intranuclear labelling and the appearance of intranuclear speckles of intense fluorescence, indicating a high local concentration of mRNA. Notably, this occurred in nuclei that had a normal chromatin distribution as assessed by Hoechst counterstaining. Cells with condensed nuclei were not labelled by oligo-dT, indicating that at this stage the mRNA 
A

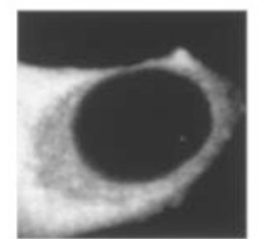

control

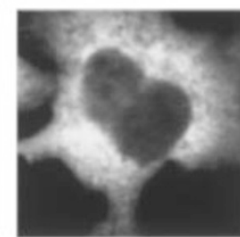

STS

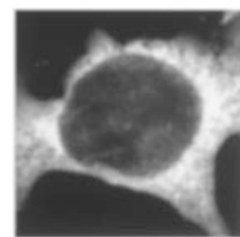

$S T S+z V A D$
B

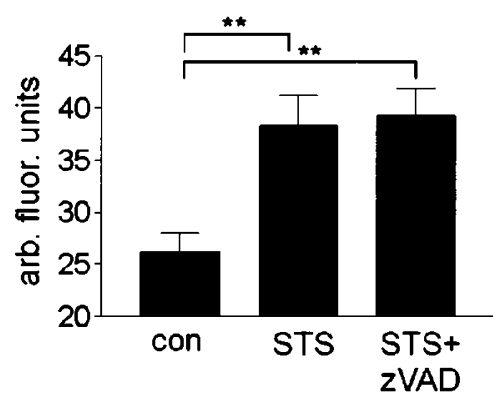

Figure 9 The nucleus of cells undergoing apoptosis becomes permeable to $70 \mathrm{kD}$ fluorescent dextran. (A) Confocal images of HeLa cells after cytoplasmic microinjection of $70 \mathrm{kD}$ dextran and stimulation with staurosporine (STS) in the absence or presence of zVAD-fmk. (B) Evaluation of nuclear fluorescence. The average pixel intensity over the nuclear area was calculated using the MCID image analysis software. Data were collected from three different experiments. 15-20 nuclei were scored in each experiment. Statistical significance was calculated using the Student's $t$-test. ${ }^{* \star} P<0.05$
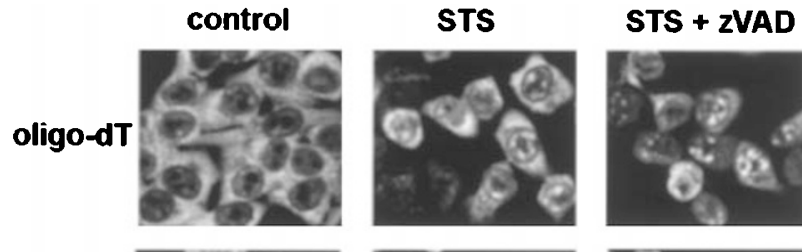

H-33342
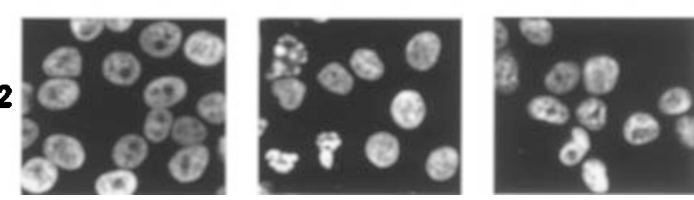

Figure 10 Intranuclear poly $(A)^{+}-$RNA accumulation in apoptosis. HeLa cells were stimulated with staurosporine (STS) in the absence or presence of ZVADfmk. After $1.5 \mathrm{~h}$ they were fixed and subjected to in situ hybridisation with a biotin-oligo-d $(T)_{45}$-mer. The upper panel shows the distribution of the poly $(A)^{+}$ RNA, the lower panel the DNA stained with Hoechst-33342

had been degraded. Preincubation with zVAD-fmk, which prevented nuclear fragmentation as well as nucleoporin cleavage (see Figures 1 and 3 ), had no effect on the redistribution of the mRNA-specific fluorescence signal. This excludes the possibility that the Nup153 and Tpr fragments produced in apoptosis are responsible for nuclear mRNA accumulation.

\section{Discussion}

The caspase family of cysteine proteases executes apoptosis in many cell systems. ${ }^{51}$ While death may in some cases intervene also in caspase-inhibited cells, ${ }^{52}$ caspase-mediated proteolysis is responsible for the classical morphology of the apoptotic demise. In particular, the relevant changes, occurring in the nucleus of apoptotic cells, are believed to require caspase activity. This has supported the idea that nuclear alterations are situated downstream to the major signalling and controlling pathways of the apoptotic programme.

Here we show that factors which control nucleocytoplasmic transport, redistribute between the nucleus and the cytoplasm prior to caspase activation, as measured by DEVD-afc cleavage, and independently from caspasemediated cleavage of nuclear proteins. Furthermore, we also show that early in apoptosis permeability of the nuclear pore complex changes, rendering it more permeable for larger-sized dextran molecules normally excluded in non-apoptotic cells. At the same time, we find that mRNA accumulates into the nucleus. This implies that a cytoplasmic/nuclear signalling system may induce early nuclear dysfunction upstream or independently from the pathways leading to caspase activation.

\section{Nucleoporin cleavage by caspases}

Our results show that the peripheral nucleoporins Nup153, RanBP2, Nup214 and Tpr are cleaved by caspase as part of the proteolytic degradation of the nucleus. Two of these nucleoporins, namely Nup153 and Tpr are located on the nucleoplasmic side of the nuclear pore where they represent components of the nuclear basket and the pore-attached intranuclear filaments, respectively. ${ }^{11,53}$ They both have been shown to bind importin $\beta$, although with different binding characteristics, and have been reported to be involved in mRNA export. ${ }^{13,39,54}$ Nup153 has also been shown to bind Ran and to play a role in multiple types of nuclear import and export. ${ }^{15,55}$

RanBP2 is localised to the filaments which emanate from the nuclear pore on its cytoplasmic side ${ }^{23,24}$ and associates with RanGAP1. RanBP2 constitutes probably the principal site where transport receptor/Ran-GTP complexes are disassembled and Ran-bound GTP is hydrolysed, which allows export receptors to release their cargo and import receptors to bind another import substrate (reviewed $\mathrm{in}^{33}$ ). Nup214 is also located on the cytoplasmic side of the nuclear pore and is essentially required for nucleocytoplasmic transport. ${ }^{56}$ Nup214 has been shown to bind the export receptor exportin 1 in a Ran-GTP dependent manner. ${ }^{57}$ Therefore, it seems conceivable, that cleavage of these nucleoporins may shut down or alter the efficiency of Ran- and importin/exportin dependent nuclear transport as part of the nuclear execution programme. In this respect, it is interesting to notice that the Nup153, $130 \mathrm{kD}$ fragment still contains the Ran and importin $\beta$ binding regions, but lacks the NPC binding domain, and therefore will likely dissociate from the NPC.

In contrast, it is unknown which part of Tpr represents the binding site for importin $\beta^{39}$ and consequently, whether this part is proteolytically removed from the region containing the protein's nuclear pore complex binding domain. The latter is known to reside within the $190 \mathrm{kD}$ 
caspase cleavage product ${ }^{54,58}$ (Cordes, unpublished data), meaning that this fragment may remain associated with the NPC.

The apparent discrepancy between the electrophoretic mobility of the two Tpr fragments of $190 \mathrm{kD}$ and $200 \mathrm{kD}$ and the calculated molecular mass of the putative cleavage products (cleavage sites: $D_{1890}$ and $D_{1997}$ or $D_{2011}$ ) being $210 \mathrm{kD}$ and 222 or $223 \mathrm{kD}$, may be due to an abnormal mobility of these polypeptides in SDS gel electrophoresis. However, we cannot exclude that Tpr may have additional cleavage sites that do not fit the known consensus sequences recognised by caspases.

Nup153 and Tpr are cleaved in vitro by caspase 3 and caspase 1, respectively, yielding an identical cleavage pattern to that observed in cells. While caspase 3 is known to process a wide variety of substrates, there is only one other nuclear substrate cleaved by caspase 1 besides Tpr. This is the transcriptional factor NF-E2, whose biological role is unclear. ${ }^{59}$

Another nucleoporin, p62, which is also considered to play an important role in nucleocytoplasmic transport, was not degraded in apoptosis, although it contains at least two consensus sequences for caspase recognition in its carboxyterminal domain. Whether this protein is protected from degradation by caspases due to its central location within the NPC and its complex formation with other nucleoporins ${ }^{60,61}$ remains unknown.

\section{Increase of nuclear pore permeability and redistribution of transport factors in cells undergoing apoptosis}

Prior to the cleavage of the four nucleoporins we observed an increased permeability of the nuclear envelope to $70 \mathrm{kD}$ dextran, which was insensitive to caspase inhibition. Variations of the diffusion limit of the nuclear pore may be reversible and subjected to regulation. This is suggested by the observation that changes in the pore diffusion limit to goldcoated particles occur in cells that transit from a quiescent to a proliferating or to a transformed state. ${ }^{62,63}$ In addition, intracellular signals such as changes in nuclear calcium levels seem to modulate the passage of intermediate sized dextrans $(10-70 \mathrm{kD})$ through the nuclear pore. ${ }^{64}$ The pathophysiological implications of changes in nuclear permeability remain unclear. One possible effect of increasing the pore radius in apoptotic cells may be to facilitate the transfer to the nucleus of relevant signals prior to the activation of the caspase execution machinery, and independently of the possible alterations in nucleocytoplasmic transport.

The observed redistribution of Ran, importin $\alpha$ and importin $\beta$ may indeed be indicative that the import and export mechanisms controlling the differential localisation of these proteins may be disturbed in cells undergoing apoptosis. Although, since Ran still accumulates in the nucleus and RanGAP1 correctly localises at the NPC in STS-treated cells, at least this part of the Ran system may still be functional. A major disturbance of nuclear import may instead occur in ActD treated cells, where importin $\alpha$ appears to be sequestrated in dense nuclear bodies, from where it is most likely not accessible for its own export receptor CAS. ${ }^{65}$ Block of importin $\alpha$ export from the nucleus may negatively affect the import of classical-NLS dependent substrates, since they would lack their interaction partner in the cytosol.

\section{poly $(A)^{+}-$RNA accumulation in cells undergoing apoptosis}

In cells stimulated to undergo apoptosis, mRNA accumulated into the nucleus independently from caspase activation and prior to detectable chromatin rearrangements (Figure 10). Several mechanisms could be responsible for intranuclear mRNA accumulation. Among them are the modification or degradation of essential export factors like $\mathrm{TAP}^{66}$ or the disturbance of the maturation and transport of hnRNP, which are the major mRNA carriers in eukaryotic cells. ${ }^{67}$ Since premRNA needs to be properly spliced before export may occur, $^{68}$ it may also be possible that the increase in the poly $(A)^{+}-$RNA-specific signal observed in preapoptotic nuclei reflects an accumulation of improperly spliced transcripts. This assumption would also be consistent with the observation that the poly $(\mathrm{A})^{+}$-RNA-specific signal is largely localised in discrete intranuclear spots, which might represent premRNA retained by the splicing machinery.

Independently of the underlying mechanisms, the early nuclear accumulation of poly- $(A)^{+}-$RNA after apoptotic stimulation may itself contribute to the propagation of the apoptotic signal, for example, by suppressing the synthesis of short lived repressors of the apoptotic pathway. This may represent an additional caspase-independent amplification system that would reinforce mitochondrial and/or cytoplasmic signals.

\section{Relevance of caspase-dependent and -independent nuclear alterations in apoptosis}

Two independent alterations that may affect nuclear function can be suggested by our findings: (i) an early, caspaseindependent redistribution of transport factors and nuclear accumulation of mRNA and (ii) a secondary caspasemediated disruption of the nuclear pore itself, which may eventually result in the irreversible collapse of nucleocytoplasmic trafficking.

Active import seems to be required to translocate into the nucleus some, but not other, pro-apoptotic factors. For example, the nuclear translocation of the mitochondrial protein AIF seems to require transport through the pore. ${ }^{17}$ Several other factors, like caspases themselves, as well as caspase-activated molecules like Acinus, CAD and DEDD, have been suggested to exert their effects following import into the nucleus. ${ }^{18,22,69}$ In view of our findings, it is unlikely that factors that are produced as a consequence of caspase activation would need active nuclear import, possibly at difference with AIF, whose nuclear effects are caspaseindependent. Four major nucleoporins that are essential for nuclear import are in fact degraded simultaneously and concomitantly to the cleavage of other caspase substrates.

On the other hand, our finding that nuclear transport factors and poly- $(\mathrm{A})^{+}-\mathrm{RNA}$ redistribute well before caspase 
activation when the permeability of the NPC is also altered, strongly suggests that relevant signals may be exchanged between the nucleus and other cellular compartments in a caspase-independent fashion early during apoptosis. This may constitute an important and previously unrecognised aspect of the apoptotic programme.

\section{Materials and Methods}

\section{Cell culture and apoptosis induction}

HeLa 229 cells were grown in DMEM medium containing $5 \%$ foetal calf serum at $37^{\circ} \mathrm{C}$ in a humidified atmosphere, and passaged every 3 days by fivefold dilution into fresh medium. For induction of apoptosis, staurosporine (Sigma, Taufkirchen) and actinomycin D (Sigma, Taufkirchen) were added to a final concentration of $0.5 \mu \mathrm{M}$ and $0.5 \mu \mathrm{g} / \mathrm{ml}$ respectively. For protease inhibitor assays, cells were preincubated with the inhibitor $(100 \mu \mathrm{M}$ for all inhibitors except Z-VADfmk (N-benzyloxycarbonyl-Val-Ala-aspartyl-fluoromethylketone) $(20 \mu \mathrm{M})$ and DEVD-CHO (N-acetyl-Asp-Glu-Val-Asp-aldehyde) $(200 \mu \mathrm{M}))$ for $30 \mathrm{~min}$ before induction. All inhibitors were from Bachem Biochemica, Heidelberg, Germany.

\section{Viability assay}

HeLa cell cultures were stained with a mixture of the membrane permeant DNA dye $\mathrm{H}-33342(500 \mathrm{ng} / \mathrm{ml})$ and the membrane impermeant DNA dye SYTOX (500 nM) (Molecular Probes, Eugene, OR, USA). Cells with intact plasma membrane and characteristically condensed or fragmented nuclei were scored as apoptotic. Data were collected from a minimum of three independent experiments.

\section{Measurement of caspase activity}

Caspase-3-like activity (measured by DEVD-afc (N-acetyl-Asp-GluVal-aspartyl-aminofluoro-methylcoumarine) cleavage) was assayed essentially as described before. ${ }^{70,71}$ Cells were lysed in $25 \mathrm{mM}$ HEPES $\mathrm{pH} 7.5,5 \mathrm{mM} \mathrm{MgCl}_{2}, 1 \mathrm{mM}$ EGTA, $0.5 \%$ Triton X-100. The fluorimetric assay was carried out in microtiter plates with a substrate concentration of $40 \mu \mathrm{M}$ and a total protein amount of $3-4 \mu \mathrm{g}$. Cleavage of DEVD-afc was followed in reaction buffer (50 mM HEPES $\mathrm{pH} 7.5,10 \mathrm{mM}$ DTT, $1 \%$ sucrose, $0.1 \%$ CHAPS) over a period of $20 \mathrm{~min}$ at $37^{\circ} \mathrm{C}$ with $\lambda_{\mathrm{ex}}=390 \mathrm{~nm}$ and $\lambda_{\mathrm{em}}=505 \mathrm{~nm}$, and the activity was calibrated with afc-standard solutions. Measurements were run in triplicate and repeated at least three times.

\section{Antibodies}

Mab414 (BAbCO, Richmond, CA, USA) $\alpha$-lamin B (Calbiochem, Schwalbach), $\alpha$-PARP (Clone C2-10, Pharmingen/Becton Dickinson, Hamburg, Germany), $\alpha$-RCC1 (Santa Cruz Biotechnology, CA, USA) and $\alpha$-importin $\beta$ (Alexis, San Diego, CA, USA) were obtained commercially. $\alpha$-CAN/Nup214 was a generous gift from $R$ Kehlenbach.

Synthetic peptides for immunisation were synthesised by $\mathrm{t}$-Boc chemistry and coupled via carboxy- or aminoterminal cysteine residues to maleimide-activated keyhole limpet hemocyanin as described. ${ }^{53}$ Nup153 peptides correspond to amino acids (aa) $21-$ 36 ( $\alpha$-Nup153-1) and aa 391-404 ( $\alpha$-Nup153-3) of the human sequence. $^{72}$ The RanBP2 peptide corresponds to aa $2285-2314$ of human RanBP2/Nup358. ${ }^{24}$ Human Tpr peptides correspond to aa $1622-1640(\alpha-T p r-1)$ and to aa 2063-2084 ( $\alpha-T p r-2)$ of the 2363-aa
Tpr sequence. Immunisation of guinea-pigs and affinity purification of antibodies was as reported earlier. ${ }^{53}$ The mouse monoclonal antibody PF190x7A8 reactive with Nup153 has been described. ${ }^{10} \alpha$-RanGAP1 antibodies were raised in rabbits against the purified recombinant human protein as described for the $\alpha$-importin $\alpha$ and $\alpha$-Ran antibodies. $^{43}$

\section{SDS gel electrophoresis and immunoblotting}

For the analysis of nuclear pore proteins, SDS-PAGE was performed according to Thomas and Kornberg. ${ }^{73}$ Proteins were blotted onto nitrocellulose using a wetblot chamber (Biorad Trans-Blot Cell) and the filters then incubated overnight at $4^{\circ} \mathrm{C}$ in TNT $(50 \mathrm{mM}$ Tris $\mathrm{pH} 8.0$, $150 \mathrm{mM} \mathrm{NaCl}, 0.05 \%$ Tween 20) containing 5\% milk-powder. Incubation with primary antibody was overnight at $4^{\circ} \mathrm{C}$. Filter washings were in TNT.

For lamin and PARP immunoblots, proteins were separated on $12 \%$ Laemmli-polyacrylamide gels and then blotted onto nitrocellulose in a Bio-Rad Semidry Blotter. Incubations and washings were as above.

\section{In vitro cleavage of nuclear pore proteins}

For in vitro cleavage of Nup153, frozen permeabilised cells, prepared as described by Görlich et al., ${ }^{74}$ were washed in reaction buffer (50 mM HEPES pH 7.5, $10 \mathrm{mM}$ DTT, 1\% sucrose, 0.1\% CHAPS). For caspase 1 cleavage the reaction buffer contained $100 \mathrm{mM}$ HEPES $\mathrm{pH} 7.5,10 \%$ sucrose, $10 \mathrm{mM}$ DTT and $0.1 \%$ CHAPS. $4-6 \times 10^{4}$ cells (corresponding to $80-100 \mu \mathrm{g}$ of total protein) were mixed with $200 \mathrm{ng}$ of purified caspase 1, 3, 4, 7 or 8 in $20 \mu$ of reaction buffer. After $1 \mathrm{~h}$ incubation at $37^{\circ} \mathrm{C}$, the cells were pelleted, resuspended in sample buffer and analyzed by SDS-PAGE.

For the analysis of Tpr cleavage, washing and incubation steps had to be minimised due to the intrinsic instability of the protein. Cells were permeabilised in 96-well plates on ice for $5 \mathrm{~min}$ with $40 \mu \mathrm{g} / \mathrm{ml}$ digitonin. The digitonin containing solution was removed and replaced by $20 \mu \mathrm{l}$ of reaction buffer containing recombinant caspases. After $30 \mathrm{~min}$ at $37^{\circ} \mathrm{C}$, the plate was briefly centrifuged at $4^{\circ} \mathrm{C}$, the supernatant was removed and the reaction stopped by addition of hot sample buffer.

Caspase 1 and 8 were kindly provided by DW Nicholson, caspase 4 and 7 by R Talanian and caspase 3 by FO Fackelmeyer.

\section{Immunocytochemistry}

HeLa cells grown on coverslips were fixed in $4 \%$ freshly prepared paraformaldehyde in PBS (10 min). Cells were then washed with $50 \mathrm{mM} \mathrm{NH}_{4} \mathrm{Cl}$ in PBS, followed by two washes in PBS, permeabilised in $0.1 \%$ Triton X-100 in PBS for 5 min and again washed twice in PBS. For Ran immunostaining, permeabilisation was in $0.1 \%$ Triton $+0.02 \%$ SDS.

Incubations with primary antibodies were for $30 \mathrm{~min}$, followed by extensive washes in PBS. Incubations with Alexa 594 coupled secondary antibodies (Molecular Probes, Eugene, OR, USA) were for $20 \mathrm{~min}$. Nuclei were counterstained with Hoechst-33342 at $125 \mathrm{ng} /$ $\mathrm{ml}$ final concentration. Coverslips were mounted in Glycerol/DABCO/ PBS and analyzed with a Leica TCS confocal microscope.

\section{In situ hybridisation}

Fluorescence in situ hybridisation of HeLa cells employing a biotinylated oligo-dT 45mer (MWG Biotech, Ebersberg) was carried out according to Huang et al. ${ }^{75}$ Cells grown on coverslips were fixed 
for $15 \mathrm{~min}$ at room temperature in 3\% paraformaldehyde in PBS. After three 15 min washes in PBS, the cells were permeabilised for 5 min on ice in pre-cooled $0.5 \%$ Triton X-100 in PBS. After three 5 min washes in PBS, coverslips were inverted onto $50 \mu$ l of hybridisation mix and incubated overnight at $42^{\circ} \mathrm{C}$ in a humidified chamber. The hybridisation mix consisted of $2 \times$ SSC containing $1 \mathrm{mg} / \mathrm{ml} E$. coli tRNA, $10 \%$ dextran sulphate, $25 \%$ formamide and $50 \mu \mathrm{g} / \mathrm{ml}$ biotinoligo dT(45). After hybridisation, the cells were washed three times for $15 \mathrm{~min}$ at $42^{\circ} \mathrm{C}$ in $2 \times \mathrm{SSC}$ and once for $15 \mathrm{~min}$ at $42^{\circ} \mathrm{C}$, in $0.5 \times \mathrm{SSC}$. For detection, cover slips were first incubated with $50 \mu$ l blocking solution $(4 \times$ SSC, $30 \mathrm{mg} / \mathrm{ml} \mathrm{BSA}$ (Roche Biochemicals) $0.1 \%$ Tween 20) for $30 \mathrm{~min}$ at room temperature in a humidified chamber, followed by incubation with detection solution $(4 \times \mathrm{SSC}, 10 \mathrm{mg} / \mathrm{ml} \mathrm{BSA}, 0.1 \%$ Tween 20, $10 \mu \mathrm{g} / \mathrm{ml}$ FITC-Avidin (Vector Laboratories)) under the same conditions. After three 5 min washes in $4 \times$ SSC/0.1\% Tween 20 at $40^{\circ} \mathrm{C}$, cover slips were stained with $125 \mathrm{ng} / \mathrm{ml}$ Hoechst-33342 and mounted on a drop of Glycerol/DABCO/PBS. Fluorescent images were recorded on a Leica TCS confocal microscope.

\section{Microinjection of fluorescent dextran}

Microinjection was performed with a semi-automated system (Eppendorf-Netheler-Hinz GmbH, Hamburg, Germany). HeLa cells were grown onto glass-bottomed petri dishes. Prior to injection, the culture medium was replaced by fresh culture medium buffered with 25 mM HEPES, pH 7.0. TexasRed-labelled dextran (Molecular Probes Eugene, OR, USA) was microinjected into the cytoplasm, the cells were then allowed to recover for $2 \mathrm{~h}$ in fresh medium and stimulated with $0.5 \mu \mathrm{M}$ STS to undergo apoptosis. For caspase inhibition, cells were incubated for $30 \mathrm{~min}$ with $20 \mu \mathrm{M}$ z-VAD-fmk prior to stimulation. One and a half hours after the addition of STS, images were recorded using a Leica TCS confocal microscope. All images were taken at similar laser intensity and instrument settings.

\section{Evaluation of nuclear fluorescence}

Images of microinjected cells were evaluated using the MCID image analysis software (Imaging Research Inc., Canada). A total of 50-60 nuclei from three independent experiments was scored. All images were background corrected and for each cell, the average fluorescence level was measured in a region of interest corresponding to the area of the nucleus. Statistical significance was calculated using the Student's $t$-test.

\section{Acknowledgements}

We thank A Tabbert and S Jäkel for support, R Kehlenbach for the $\alpha$ CAN/Nup214 antibody and DW Nicholson, FO Fackelmayer and R Talanian for providing recombinant caspases.

\section{References}

1. Wyllie AH, KerrJF and Currie AR (1980) Cell death: the significance of apoptosis. Int. Rev. Cytol. 68: 251-306

2. Oberhammer FA, Hochegger K, Fröschl G, Tiefenbacher R and Pavelka M (1994) Chromatin condensation during apoptosis is accompanied by degradation of lamin $A+B$, without enhanced activation of cdc2 kinase. J. Cell Biol. 126: 827-837

3. Lazebnik YA, Takahashi A, Moir RD, Goldman RD, Poirier GG, Kaufmann SH and Earnshaw WC (1995) Studies of the lamin proteinase reveal multiple paralle biochemical pathways during apoptotic execution. Proc. Natl. Acad. Sci. USA 92: 9042-9046
4. Göhring F, Schwab BL, Nicotera P, Leist M and Fackelmayer FO (1997) The novel SAR-binding domain of scaffold attachment factor A (SAF-A) is a target in apoptotic nuclear breakdown. EMBO J. 16: 7361-7371

5. Schwab BL, Leist M, Knippers R and Nicotera $P$ (1998) Selective proteolysis of the nuclear replication factor MCM3 in apoptosis. Exp. Cell Res. 238: 415-421

6. Rheaume E, Cohen LY, Uhlmann F, Lazure C, Alam A, Hurwitz J, Sekaly RP and Denis $F(1997)$ The large subunit of replication factor $C$ is a substrate for caspase3 in vitro and is cleaved by a caspase-3-like protease during Fas-mediated apoptosis. EMBO J. 16: 6346-6354

7. Szabo C and Dawson VL (1998) Role of poly(ADP-ribose)-synthetase in inflammation and ischaemia-reperfusion. Trends Pharmacol. Sci. 19: 287-298

8. Buendia B, Santa-Maria A and Courvalin JC (1999) Caspase-dependent proteolysis of integral and peripheral proteins of nuclear membranes and nuclear pore complex proteins during apoptosis. J. Cell Sci. 112: 1743-1753

9. Sukegawa J and Blobel $G$ (1993) A nuclear pore complex protein that contains zinc finger motifs, binds DNA, and faces the nucleoplasm. Cell 72: 29-38

10. Cordes VC, Reidenbach S, Köhler A, Stuurman N, van Driel R and Franke WW (1993) Intranuclear filaments containing a nuclear pore complex protein. J. Cell Biol. 123: 1333-1344

11. Pante N, Bastos R, McMorrow I, Burke B and Aebi U (1994) Interactions and three-dimensional localization of a group of nuclear pore complex proteins. J. Cell Biol. 126: 603-617

12. Shah $S$ and Forbes DJ (1998) Separate nuclear import pathways converge on the nucleoporin Nup153 and can be dissected with dominant-negative inhibitors. Curr. Biol. 8: $1376-1386$

13. Bastos R, Lin A, Enarson M and Burke B (1996) Targeting and function in mRNA export of nuclear pore complex protein Nup153. J. Cell Biol. 134: 1141-1156

14. Saitoh H, Cooke CA, Burgess WH, Earnshaw WC and Dasso M (1996) Directand indirect association of the small GTPase Ran with nuclear pore proteins and soluble transport factors: studies in Xenopus leavis oocytes. Mol. Biol. Cell 7: $1319-1334$

15. Nakielny S, Shaikh S, Burke B and Dreyfuss G (1999) Nup153 is an M9containing mobile nucleoporin with a novel Ran-binding domain. EMBO J. 18: 1982-1995

16. Yasuhara N, Eguchi $Y$, Tachibana $T$, Imamoto $N$, Yoneda $Y$ and Tsujimoto $Y$ (1997) Essential role of active nuclear transport in apoptosis. Genes Cells 2: 5564

17. Susin SA et al. (1999) Molecular characterization of mitochondrial apoptosisinducing factor. Nature 397: 441-446

18. Sahara S, Aoto M, Eguchi Y, Imamoto N, Yoneda $Y$ and Tsujimoto $Y$ (1999) Acinus is a caspase-3-activated protein required for apoptotic chromatin condensation. Nature 401: 168-173

19. Kearse KP and Hart GW (1991) Lymphocyte activation induces rapid changes in nuclear and cytoplasmic glycoproteins. Proc Natl Acad Sci USA 88: 1701-1705

20. Mao P-L, Jiang Y, Wee BY and Porter AG (1998) Activation of caspase-1 in the nucleus requires nuclear translocation of pro-caspase-1 mediated by its prodomain. J. Biol. Chem. 273: 23621-23624

21. Colussi PA, Harvey NL and Kumar S (1998) Prodomain-dependent nuclear localization of the caspase-2 (Nedd2) precursor. J. Biol. Chem. 273: 2453524542

22. Enari M, Sakahira H, Yokoyama H, Okawa K, Iwamatsu A and Nagata S (1998) A caspase-activated DNase that degrades DNA during apoptosis, and its inhibitor ICAD. Nature 391: 43-50

23. Wu J, Matunis MJ, Kraemer D, Blobel G and Coutavas E (1995) Nup358, a cytoplasmically exposed nucleoporin with peptide repeats, Ran-GTP binding sites, zinc fingers, a cyclophilin A homologous domain, and a leucine-rich region. J. Biol. Chem. 270: 14209-14213

24. Yokoyama N (1995) A giant nucleopore protein that binds Ran/TC4. Nature 376: $184-188$

25. Wilken N, Senecal JL, Scheer U and Dabauvalle MC (1995) Localization of the Ran-GTP binding protein RanBP2 at the cytoplasmic side of the nuclear pore complex. Eur. J. Cell Biol. 68: 211-219

26. Kraemer D, WozniakRW, Blobel G and Radu A (1994) The human CAN protein, a putative oncogene product associated with myeloid leukemogenesis, is a nuclear pore complex protein that faces the cytoplasm. Proc. Natl. Acad. Sci. USA 91: $1519-1523$

27. Davis LI and Blobel G (1986) Identification and characterization of a nuclear pore complex protein. Cell 45: 699-709 
28. Cordes VC, Waizenegger I and Krohne G (1991) Nuclear pore complex glycoprotein p62 of Xenopus laevis and mouse: cDNA cloning and identification of its glycosylated region. Eur. J. Cell Biol. 55: 31-47

29. Carmo-Fonseca M, Kern H and Hurt EC (1991) Human nucleoporin p62 and the essential yeast nuclear pore protein NSP1 show sequence homology and a similar domain organization. Eur. J. Cell Biol. 55: 17-30

30. Grote M, Kubitscheck U, Reichelt R and Peters R (1995) Mapping of nucleoporins to the center of the nuclear pore complex by post-embedding immunogold electron microscopy. J. Cell Sci. 108: 2963-2972

31. Cordes VC, Reidenbach S, Rackwitz HR and Franke WW (1997) Identification of protein p270/Tpr as a constitutive component of the nuclear pore complexattached intranuclear filaments. J. Cell Biol. 136: 515-529

32. Zimowska G, Aris JP and Paddy MR (1997) A Drosophila Tpr protein homolog is localized both in the extrachromosomal channel network and to nuclear pore complexes. J. Cell Sci. 110: $927-944$

33. Gorlich D and Kutay U (1999) Transport between the cell nucleus and the cytoplasm. Annu. Rev. Cell Dev. Biol. 15: 607-660

34. Weil M, Jacobson MD, Coles HSR, Davies TJ, Gardner RL, Raff KD and Raff MC (1996) Constitutive expression of the machinery for programmed cell death. J. Cell. Biol. 133: 1053-1059

35. Fujita T, Ishido S, Muramatsu S, Itoh M and Hotta H (1996) Suppression of actinomycin D-induced apoptosis by the NS3 protein of hepatitis C virus. Biochem. Biophys. Res. Commun. 229: 825-831

36. Garcia-Calvo M, Peterson EP, Leiting B, Ruel R, Nicholson DW and Thornberry NA (1998) Inhibition of human caspases by peptide-based and macromolecular inhibitors. J. Biol. Chem. 273: 32608-32613

37. Moroianu J, Blobel G and Radu A (1997) RanGTP-mediated nuclear export of karyopoherin alpha involves its interaction with the nucleoporin Nup153. Proc. Natl. Acad. Sci. USA 94: 9699-9704

38. Chi NC and Adam SA (1997) Functional domains in nuclear import factor p97 for binding the nuclear localization sequence receptor and the nuclear pore. Mol. Biol. Cell 8: 945-956

39. Shah S, Tugendreich S and Forbes D (1998) Major binding sites for the nuclear import receptor are the internal nucleoporin Nup153 and the adjacent nuclear filament protein Tpr. J. Cell Biol. 141: $31-49$

40. Bischoff FR, Klebe C, Kretschmer J, Wittinghofer A and Ponstingl H (1994) RanGAP1 induces GTPase activity of nuclear Ras-related Ran. Proc. Natl. Acad. Sci. USA 91: 2587-2591

41. BischoffFR and Ponstingl $H$ (1991) Catalysis of guanine nucleotide exchange on Ran by the mitotic regulator RCC1. Nature 354: 80-82

42. Chi NC, Adam EJ and Adam SA (1995) Sequence and characterization of cytoplasmic nuclear protein import factor p97. J. Cell Biol. 130: 265-274

43. Görlich D, Vogel F, Mills AD, Hartmann E and Laskey RA (1995) Distinct functions for the two importin subunits in nuclear protein import. Nature 377: $246-248$

44. Matunis MJ, Coutavas E and Blobel G (1996) A novel ubiquitin-like modification modulates the partitioning of the Ran-GTPase-activating protein RanGAP1 between the cytosol and the nuclear pore complex. J. Cell Biol. 135: 1457-1470

45. Delphin C, Guan T, Melchior F and Gerace L (1997) RanGTP targets p97 to RanBP2, a filamentous protein localized at the cytoplasmic periphery of the nuclear pore complex. Mol. Biol. Cell 8: 2379-2390

46. Mahajan R, Delphin C, Guan T, Gerace L and Melchior F (1997)A small ubiquitinrelated polypeptide involved in targeting RanGAP1 to nuclear pore complex protein RanBP2. Cell 88: 97-107

47. Saitoh H, Pu R, Cavenagh M and Dasso M (1997) RanBP2 associates with Ubc9p and a modified form of RanGAP1. Proc. Natl. Acad. Sci. USA 94: $3736-$ 3741

48. Ohtsubo M, Okazaki H and Nishimoto T (1989) The RCC1 protein, a regulator for the onset of chromosome condensation locates in the nucleus and binds to DNA. J. Cell Biol. 109: 1389-1397

49. Li P, Nijhawan D, Budihardjo I, Srinivasula SM, Ahmad M, Alnemri ES and Wang X (1997) Cytochrome $c$ and dATP-dependent formation of Apaf-1/Caspase-9 complex initiates an apoptotic protease cascade. Cell 91: 479-489

50. Paine PL, Moore LC and Horowitz SB (1975) Nuclear envelope permeability. Nature 254: 109 - 114
51. Cohen GM (1997) Caspases: the executioners of apoptosis. Biochem. J. 326 $1-16$

52. Leist M, Single B, Castoldi AF, Kühnle S and Nicotera P (1997) Intracellular adenosine triphosphate (ATP) concentration: a switch in the decision between apoptosis and necrosis. J. Exp. Med. 185: 1481-1486

53. Cordes VC, Reidenbach S, Rackwitz H-R and Franke WW (1997) Identification of protein p270/Tpr as a constitutive component of the nuclear pore complexattached intranuclear filaments. J. Cell Biol. 136: 515-529

54. Bangs $P$, Burke B, Powers C, Craig R, Purohit A and Doxsey S (1998) Functional analysis of Tpr: identification of nuclear pore complex association and nuclear localization domains and a role in mRNA export. J. Cell Biol. 143: 1801-1812

55. Ullman KS, Shah S, Powers MA and Forbes DJ (1999) The nucleoporin Nup153 plays a critical role in multiple types of nuclear export. Mol. Biol. Cell 10:649-664

56. van Deursen J, Boer J, Kasper L and Grosveld G (1996) G2 arrest and impaired nucleocytoplasmic transport in mouse embryos lacking the proto-oncogene CAN/Nup214. EMBO J. 15: 5574-5583

57. Askjaer P, Bachi A, Wilm M, Bischoff FR, Weeks DL, Ogniewski V, Ohno M, Niehrs C, Kjems J, Mattaj IW and Fornerod M (1999) RanGTP-regulated interactions of CRM1 with nucleoporins and a shuttling DEAD-box helicase. Mol. Cell Biol. 19: 6276-6285

58. Cordes VC, Hase ME and Müller L (1998) Molecular segments of protein Tpr that confernucleartargeting and association with the nuclear pore complex. Exp. Cell Res. 245: 43-56

59. Ohtsubo T, Kamada S, Mikami T, Murakami H and Tsujimoto Y (1999) Identification of NRF2, a member of the NF-E2 family of transcription factors, as a substrate for caspase-3(-like) proteases. Cell Death Differ. 6: 865-872

60. Buss F, Kent H, Stewart M, Bailer SM and Hanover JA (1994) Role of different domains in the self-association of rat nucleoporin p62. J. Cell Sci. 107:631-638

61. Hu T, Guan T and Gerace L (1996) Molecular and functional characterization of the p62 complex, an assembly of nuclear pore complex glycoproteins. J. Cell Biol. 134: 589-601

62. Feldherr CM and Akin D (1990) The permeability of the nuclear envelope in dividing and nondividing cell cultures. J. Cell Biol. 111: 1-8

63. Feldherr CM and Akin D (1993) Regulation of nuclear transport in proliferating and quiescent cells. Exp. Cell Res. 205: 179-186

64. Stehno-Bittel L, Perez-Terzic C and Clapham DE (1995) Diffusion across the nuclear envelope inhibited by depletion of the nuclear $\mathrm{Ca}^{2+}$ store. Science 270 : $1835-1838$

65. Kutay U, BischoffFR, Kostka S, KraftR and Görlich D (1997) Export of importin a from the nucleus is mediated by a specific nuclear transport factor. Cell 90: $1061-1071$

66. Gruter P, Tabernero C, von Kobbe C, Schmitt C, Saavedra C, Bachi A, Wilm M Felber BK and Izaurralde E (1998) TAP, the human homolog of Mex67p mediates CTE-dependent RNA export from the nucleus. Mol. Cell 1: 649-659

67. Izaurralde E and Mattaj IW (1995) RNA export. Cell 81: 153-159

68. Luo MJ and Reed R (1999) Splicing is required for rapid and efficient mRNA export in metazoans. Proc. Natl. Acad. Sci. USA 96: 14937-14942

69. Stegh AH, Schickling O, Ehret A, Scaffidi C, Peterhansel C, Hofmann TG, Grummt I, Krammer PH and Peter ME (1998) DEDD, a novel death effector domain-containing protein, targeted to the nucleolus. EMBO J. 17: 5974-5986

70. Thornberry NA (1994) Interleukin-1 beta converting enzyme. Methods Enzymol. 244: $615-631$

71. Leist M, Volbracht C, Kuhnle S, Fava E, Ferrando-May E and Nicotera P (1997) Caspase-mediated apoptosis in neuronal excitotoxicity triggered by nitric oxide. Mol. Med. 3: $750-764$

72. McMorrow I, Bastos R, Horton $H$ and Burke B (1994) Sequence analysis of a cDNA encoding a human nuclear pore complex protein, hnup153. Biochim. Biophys. Acta 1217: 219-223

73. Thomas JO and Kornberg RD (1975) An octamer of histones in chromatin and free in solution. Proc. Natl. Acad. Sci. USA 72: 2626-2630

74. Görlich D, Prehn S, Laskey RA and Hartmann E (1994) Isolation of a protein that is essential for the first step of nuclear protein import. Cell 79: 767-778

75. Huang S, Deerinck TJ, Ellisman MH and Spector DL (1994) In vivoanalysis of the stability and transport of nuclear poly $(\mathrm{A})^{+} \mathrm{RNA}$. J. Cell Biol. 126: 877-899 